\title{
Larval helminths in the invasive American brine shrimp Artemia franciscana throughout its annual cycle
}

\author{
Boyko B. Georgiev1*, Aleksandar Angelov', Gergana P. Vasileva1', Marta I. Sánchez², \\ Francisco Hortas ${ }^{3}$, Yasen Mutafchiev ${ }^{1}$, Plamen Pankov ${ }^{1}$ and Andy J. Green ${ }^{2}$
}

${ }^{1}$ Institute of Biodiversity and Ecosystem Research, Bulgarian Academy of Sciences, 2 Gagarin Street, 1113 Sofia, Bulgaria; ${ }^{2}$ Department of Wetland Ecology, Estación Biológica de Doñana, CSIC, C/Américo Vespucio s/n, E-41092 Sevilla, Spain; ${ }^{3}$ Department of Biology, Faculty of Marine and Environmental Sciences, Cádiz University, Puerto Real, Spain

\begin{abstract}
One of the best examples of rapid displacement of native species by an invader is the eradication of native Artemia salina and A. parthenogenetica in the Mediterranean by the introduced American A. franciscana. Previous studies based on sampling from limited time periods suggest that the success of the American species as a competitor may be due partly to different parasite burden, since native Artemia spp. have high cestode infection rates regulating their density. The aim of this study is to test the hypothesis that the helminth infection in A. franciscana in its invasive range is low throughout its annual life cycle. Samples of A. franciscana were collected every second month from La Tapa saltern (Andalusia) during one year. Five helminth species were recorded: cestodes Flamingolepis liguloides, F. flamingo, Gynandrotaenia stammeri (all flamingo parasites), Eurycestus avoceti (a shorebird parasite) and larval spirurids of the Acuariinae (the first record of nematodes in Artemia). The overall infection rate was low, with total prevalence $5.9 \%$ and prevalence of individual parasite species between 0.2 and $3.2 \%$. The mean abundance of helminths was $0.005-0.155$ (av. 0.068), 5-13 times lower than in native congeners. Waterbird counts indicate that the low infection rates cannot be explained by lack of definitive hosts. The results are consistent with the hypothesis that helminths have no regulating effect on the invasive brine shrimp in the Mediterranean. The replacement of the native populations by the invader can be partially explained by a competition mediated by parasites/predators through a differential impact on host fitness.
\end{abstract}

\section{Keywords}

Artemia, cestodes, nematodes, biological invasion, hypersaline wetlands, salt ponds

\section{Introduction}

Comparative studies of parasite infections in native and alien host species are important to understand the role of parasites in biological invasions (Dunn 2009; Kelly et al. 2009; Dunn et al. 2012). Brine shrimps of the genus Artemia Leach, 1819 (Crustacea: Branchiopoda) from hypersaline Mediterranean wetlands and their helminth parasites offer a promising hostparasite system for elucidating effects of parasitism on the outcome of competitive interactions during an ongoing biological invasion. The American brine shrimp A. franciscana Kellogg, 1906, originating from commercialised populations at the San Francisco Bay and Great Salt Lake in North America (Muñoz et al. 2014), has been introduced into the Western Mediterranean and has expanded its range since the 1980s, displacing the native brine shrimps A. parthenogenetica Barigozzi, 1974 and A. salina (L., 1758) (Amat et al. 2005, 2007).

Native brine shrimps in the Mediterranean are intermediate hosts of 12 species of avian cestodes parasitic as adults in flamingos, gulls, grebes, shorebirds or ducks (Gabrion et al. 1982; Thiéry et al. 1990; Robert and Gabrion 1991; Amat et al. 1991b; Mura 1995; Georgiev et al. 2005, 2007; Vasileva et al. 2009; Amarouayache et al. 2009). Both adult shrimps and metanauplii participate in cestode life cycles (Redón et al. 2011). The presence of larval tapeworms (cysticercoids) in the native brine shrimps is associated with modifications of their colouration (Thiéry et al. 1990; Amat et al. 1991a; Sánchez et al. 2006a) and altered surfacing and photophobic behaviour (Sánchez et al. 2007), thus increasing the probability of being 
eaten by definitive hosts (Sánchez et al. 2009a). The infections with cysticercoids are linked with neurological and physiological disorders of intermediate hosts, changing the lipid content and respiration rate (Amat et al. 1991a; Varó et al. 2000; Sánchez et al. 2009b). Infected brine shrimps exhibit enhanced swarming propensity that may also increase the probability for transmission by predation (Rode et al. 2013). Isotopic studies indicate that cysticercoid infections can change the selective utilisation of trophic resources by native brine shrimps (Sánchez et al. 2013a). Furthermore, cestode larvae reduce the fecundity of the infected Artemia (Amat et al. 1991a; Sánchez et al. 2012).

Two previous studies in the Western Mediterranean have demonstrated that cestode infection rates in invasive brine shrimps are lower than in their native congeners. Georgiev et al. (2007) screened cestode infections in 7 populations of Artemia spp. (3 invasive and 4 native) along the southern Iberian coast in summer 2005; they found that the invasive populations were less infected than native ones. Sánchez et al. (2012) examined cestode infections in A. franciscana and A. parthenogenetica in a rare case of syntopy (co-occurrence) in Aigûes-Mortes wetland, France, in summer and winter 2008. The invader showed considerably reduced cestode parasite diversity, prevalence and abundance. However, both studies were based on sampling from limited time periods, and characterisation of the infections in A. franciscana throughout the annual life cycle has not previously been carried out anywhere in the invasive or native range of this New World species. In contrast, a recent study from two sites in southern Spain found consistently high levels of cestode infections in native A. salina (325 km to the east of our study site) and A. parthenogenetica $(90 \mathrm{~km}$ to the northwest) throughout their annual cycle, which were partly related to the density and biomass of avian definitive hosts (Sánchez et al. 2013b).

The aim of the present study is to quantify the helminth infection in A. franciscana at a site in its invasive range throughout its annual life cycle. We also compared data on cestode infections with the abundance of waterbirds, in order to establish if low infection levels can be explained by a lack of appropriate avian hosts. We discuss our results in relation to the findings of the previous studies of helminths in native and invasive Artemia.

\section{Materials and Methods}

Samples of Artemia franciscana were collected from a precrystallization pond (local name $13 \mathrm{~N}, 3.67 \mathrm{ha}, 36^{\circ} 35.799^{\prime} \mathrm{N}$, $6^{\circ} 12.597^{\prime} \mathrm{W}$ ) of La Tapa saltern (400 ha) near El Puerto de Santa María, Cádiz Province (Andalusia), on the Atlantic coast of Spain, between December 2006 and September 2007 (1 December 2006, 19 February, 26 April, 26 June and 18 September 2007). The salinity of this pond ranged between 86 and $209 \mathrm{~g} \mathrm{l}^{-1}$ during the study (Unión Salinera de España, S.A., unpublished data). This saltern is used for industrial salt pro- duction (Hortas 1997) and is in the Cádiz Bay Natural Park. All waterbirds present at La Tapa salterns were counted on a monthly basis throughout 2006 and 2007 (Consejería de Medio Ambiente 2007). The study pond consistently held high numbers of waterbirds (personal observations).

Sampling was carried out from close to the shoreline with a $0.5 \mathrm{~mm}$ mesh sweep net, and the brine shrimps were preserved in $80 \%$ alcohol. From each sample, 200 adult individuals were examined for parasites, except for September 2007 when only 149 individuals were present in the sample. The brine shrimps were prepared as temporary glycerol mounts and examined under the stereomicroscope or compound microscope. If the identification of the larval cestodes (cysticercoids) was not possible at this stage, they were isolated by preparatory needles and mounted in Berlese's medium to facilitate observations on the morphology of rostellar hooks. Identification of cysticercoids followed Robert and Gabrion (1991), Georgiev et al. (2005) and Vasileva et al. (2009). Larval nematodes were studied in temporary glycerol mounts.

In order to characterise the parasite infections, we measured the prevalence (P: proportion of individuals infected), the mean abundance (MA: number of cysticercoids averaged for all brine shrimp individuals) and the mean intensity (MI: number of cysticercoids averaged for all infected brine shrimp individuals) for the overall parasite infection and for each parasite species (see Bush et al. 1997 for detailed definitions of infection descriptors).

Statistical analyses were conducted using Statistica 6.0 (StatSoft 2001).

\section{Results}

Larvae of five helminth species were recorded in A. franciscana in La Tapa saltern. These included cysticercoids of four cestode species, three of which are parasitic as adult in greater flamingos Phoenicopterus roseus: Flamingolepis liguloides (Fig. 1a,b) and F. flamingo (Skrjabin, 1914) (Fig. 1c) of the family Hymenolepididae, and Gynandrotaenia stammeri Fuhrmann, 1936 (Fig. 1e,f) of the family Progynotaeniidae. Eurycestus avoceti Clark, 1954 of the family Dilepididae (Fig. 1d) is a parasite of avocets Recurvirostra avosetta, blackwinged stilts Himantopus himantopus and Kentish plovers Charadrius alexandrinus. In addition, third-stage larvae of spirurid nematodes (referred to from hereon as "Acuariinae gen. sp.") were found (Fig. 1g, h). These were a morphologically homogeneous series (probably representing one species) and exhibited the presence of muscular and glandular portions of the oesophagus (as in the order Spirurida), lateral triangular pseudolabia, elongate buccal cavity and cordons arising from the bases of pseudolabia (as in the subfamily Acuariinae of the family Acuariidae) (Chabaud 1975, Anderson 2000).

The overall infection rate was low, with total prevalence $5.9 \%$ and values of the prevalence of the individual parasite species varying between 0.2 and $3.2 \%$; the mean abundance 




Fig. 1. Larvae of helminth parasites recorded in Artemia franciscana from La Tapa: a - Flamingolepis liguloides (Hymenolepididae), three cysticercoids in the abdomen of Artemia. b-F. liguloides, a detail demonstrating the shape of the rostellar hooks. c - Flamingolepis flamingo (Hymenolepididae), a cysticercoid in the haemocoel of Artemia. d-Eurycestus avoceti (Dilepididae), a cysticercoid in a thoracopod of Artemia. e, f-Gynandrotaenia stammeri (Progynotaeniidae), cysticercoids in the haemocoel of Artemia; note armament of suckers (arrow). $\mathbf{g}$ - Nematode larva of the subfamily Acuariinae in the haemocoel of Artemia, general view. $\mathbf{h}$ - Nematode larva of the subfamily Acuariinae, cephalic end, lateral view, demonstrating the triangular pseudolabium typical for the family

was also low (Table I). The number of the helminth species varied between one in April and four in February and September. The only parasite species recorded in all the samples was $E$. avoceti. The most prevalent and abundant parasite was F. flamingo; however, its prevalence and mean abundance in the samples studied did not exceed $8.5 \%$ and $0.090 \pm 0.021$, respectively (maximum values from February).
In total, 65 helminth larvae were found: 31 of $F$. flamingo, 24 of E. avoceti, 4 of F. liguloides, 3 of G. stammeri and 3 of Acuariinae gen. sp. Out of 56 infected brine shrimps, 52 contained a single helminth species. Multiple infections were combinations of F. flamingo and $E$. avoceti recorded in one brine shrimp collected in December and in three sampled in February. One of the latter host individuals exhibited the 

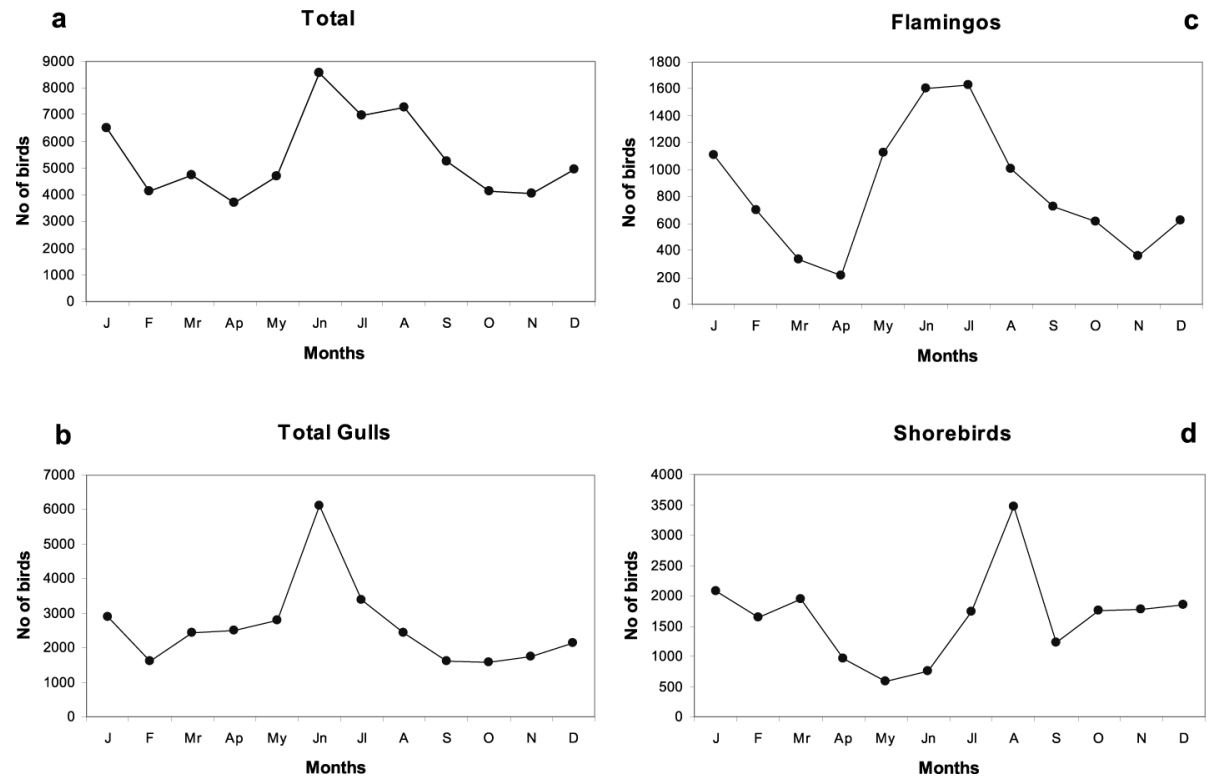

Fig. 2. Seasonal variation of waterbird numbers in La Tapa saltpans in 2006-2007, presenting mean values for two years: a - Total number of birds. $\mathbf{b}$ - Number of gulls. $\mathbf{c}$ - Number of flamingos. $\mathbf{d}$ - Number of shorebirds. See Appendix I for details of the abundance of individual species

highest intensity of infection recorded, i.e. two cysticercoids of $F$. flamingo and two of E. avoceti.

Pairwise comparisons of all the values of mean abundance and mean intensity between seasonal samples were performed using Mann-Whitney U Tests. The only significant difference detected was that between the values of the total mean abundance in February (month of peak abundance) and April 2007 $(\mathrm{U}=17499, \mathrm{p}=0.030)$. No significant differences in mean intensity were detected. The same test was applied to compare helminth infections between male and female brine shrimps as well as between three size classes of Artemia individuals ( $<6 \mathrm{~mm}$ long, $6-8 \mathrm{~mm}$ long and $8-10 \mathrm{~mm}$ long). No significant differences of the infections between sexes or size classes were revealed, although our statistical power was very low.

Of the infected 33 female brine shrimps, 21 had eggs in the ovisac $(63.6 \%)$. For the non-infected females $(n=407)$, this proportion was only $34.4 \%$. Comparing brine shrimps with eggs, there was no significant difference between the number of eggs in infected and non-infected female individuals, i.e. no evidence for reduced fecundity due to helminth infections. However, age and seasonal differences could be confounding factors here (e.g. infected individuals may tend to be older).

Waterbird counts showed that the avian community consisted of 49 species, many of them represented by substantial numbers and biomass (Appendix I). Waterbirds were abundant throughout the year, with mean total counts varying between 3000 and 9000 (Fig. 2a). The salterns are inhabited mainly by gulls (av. 2600 individuals/month), shorebirds (av. 1650 individuals/month) and flamingos (Phoenicopterus roseus) (av. 840 individuals/month). These groups, known to be definitive hosts of cestodes using native brine shrimps as intermediate hosts, were all abundant throughout the year but with maxima in summer months (Fig. 2b-d). The abundance of grebes and common shelducks, also known as hosts of cestodes developing in Artemia, was much lower (Appendix I).

\section{Discussion}

The invasion of Artemia franciscana in the Mediterranean Region and in Asia (Amat et al. 2005, 2007; Vikas et al. 2012) has probably led to the most important biodiversity loss in hypersaline ecosystems to date. Previous studies indicating the possible role of helminth parasites as a factor promoting the competitive success of $A$. franciscana in the course of its invasion in the Mediterranean have been based on few samples and seasons (Georgiev et al. 2007; Sánchez et al. 2012). Research considering the whole annual cycle provides more reliable results, as helminth infections often vary seasonally. The present study, conducted during a full year, is the most exhaustive investigation of parasite infection in $A$. franciscana to date. In contrast to similar studies of native Artemia (Sánchez et al. 2013b), parasite infection was consistently low throughout the year, suggesting that parasites have a crucial role in the competitive success of this highly invasive species.

The cestode community detected in A. franciscana inhabiting La Tapa salterns has lower species richness (4 species) than reported for one A. franciscana population from Portugal (6 species), but higher richness than recorded at other sites from Spain (1-2 species) and France (2 species), albeit over shorter periods (Georgiev et al. 2007; Vasileva et al. 2009; Sánchez et al. 2012). In contrast, cestode communities in $A$. parthenogenetica and in A. salina studied over the whole annual cycle consisted of 9 cestode species each (Sánchez et al. 2013b). 


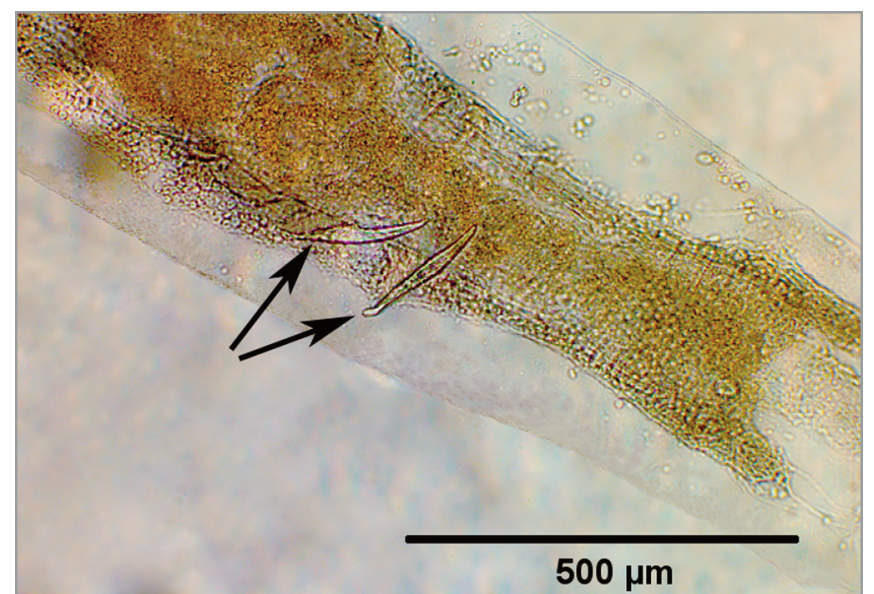

Fig. 3. Abdomen of Artemia franciscana containing isolated rostellar hooks (arrows) originating from a dead cysticercoid of Flamingolepis liguloides

Sánchez et al. (2013b) found the cestode infection rates in native $A$. parthenogenetica and $A$. salina to be high. Throughout the year, $4-45 \%$ of $A$. parthenogenetica in Odiel saltpans and $27-72 \%$ of A. salina from Salinas de Cerrillos were infected with cestodes (compared to $0.5-13 \%$ of $A$. franciscana from La Tapa). The overall mean abundance of cysticercoids varied between 0.05 and 0.81 (av. 0.35) in A. parthenogenetica and between 0.44 and 1.32 (av. 0.90) in A. salina (Sánchez et al. 2013b). This contrasts with mean abundance of helminth parasites in A. franciscana ranging between 0.005 and 0.155 (av. 0.068), i.e. 5-13 times smaller than in the native species.

Our results also demonstrate that the most prevalent and abundant cestode species in native brine shrimps, Flamingolepis liguloides, has consistently lower prevalence and abundance in the invasive $A$. franciscana throughout the year. The frequent records of dead cysticercoids (Fig. 3) in A. franciscana (unpublished data) suggest that low prevalence of F. liguloides in this brine shrimp species may be related to a strong immune response by the host. For the remaining three cestode species recorded in the present study (Flamingolepis flamingo, Gynandrotaenia stammeri and Eurycestus avoceti), the values of prevalence and abundance are generally similar in invasive and native Artemia spp. (see Sánchez et al. 2013b).

The absence of larval Fimbriarioides tadornae and Confluaria podicipina (parasitic as adults in shelducks and grebes, respectively) at La Tapa can be explained by the absence or low abundance of the appropriate definitive hosts in the wetland studied (Appendix I). However, the same explanation is not applicable for the lack of species of the genus Anomotaenia (parasitic in shorebirds), Wardium and Branchiopodataenia (both parasitic in gulls), since the relevant host groups were abundant at La Tapa (Fig. 2b,d). This suggests variation between cestode species in their ability to adapt to the new, invasive intermediate host. Furthermore, F. flamingo was consistently more abundant than F. liguloides (Table I), the inverse of what is recorded in native brine shrimps (Sánchez et al. 2013b), even though these species share the same final host. The absence of $A$. tringae in the present material is also surprising since this was the most prevalent and abundant cestode species in another $A$. franciscana population in a different area of Cádiz Bay (Georgiev et al. 2007). On this basis, we can speculate that the co-adaptation between invasive hosts and native parasites at different invaded sites has achieved different levels of development. Based on neutral genetic markers, there are important differences between the different A. franciscana populations found in the Iberian Peninsula (Muñoz et al. 2014).

The present results on parasite infection of $A$. franciscana during its entire life cycle are consistent with the previous short-term data demonstrating that the parasite infection rate is much lower in invasive than in native brine shrimp (Georgiev et al. 2007; Sánchez et al. 2012). We found no evidence of regulating effects of parasite infections on the populations of $A$. franciscana, although these are hard to detect due to the low infection rates (see also Sánchez et al. 2012). The lack of parasite-induced control on the host population contrasts strongly with parasite-associated modifications of appearance, behaviour and fecundity in the native Artemia reported previously (Thiéry et al. 1990; Amat et al. 1991a; Varó et al. 2000; Sánchez et al. 2006a, 2007, 2009b, 2012, 2013; Rode et al. 2013). Therefore, the differences of parasite burden in native and invasive brine shrimp may result into differential predator-prey outcomes (Sánchez et al. 2009a; Dunn et al. 2012), i.e. differential parasite-induced mortality. This, in combination with the reduced fecundity of infected native brine shrimps (Amat et al. 1991a; Sánchez et al. 2012), explains the competitive success of $A$. franciscana in the Mediterranean. Thus, the replacement of the native populations of Artemia spp. by the invasive species can be partially explained by a competition mediated by parasites/predators through a differential impact on host fitness.

The acuariid nematodes recorded in the course of the present study could not be identified to genus due to the relatively simple morphology of larvae, which does not resemble that of adults, as well as the limited previous studies, which are insufficient to link larval and adult stages of species in this family on the basis of morphology. Though rarely, we have also recorded similar nematode larvae in A. parthenogenetica from Odiel saltpans (Huelva Province) and from A. salina from Salinas de Cerrillos (Almería Province) (unpublished data). Genera of the Acuariinae have been differentiated on the basis of the morphology of adults, which typically occur in the stomach (under the gizzard lining), proventriculus or oesophagus of birds (Skryabin et al. 1965; Chabaud 1975). Until now, no nematode species has been reported to utilise Artemia spp. as intermediate host in its life cycle (Anderson 2000). On the basis of the species diversity and abundance of the potential definitive hosts in hypersaline wetlands, it can be speculated that the larval nematodes may belong to the genera Decorataria Sobolev in Skryabin, Shikhobalova and Sobolev, 1949 (parasitic in grebes, see Mutafchiev and Georgiev 2008a), Chevreuxia Seurat, 1918 
Table I. Prevalence (P\%), mean abundance $(\mathrm{MA} \pm \mathrm{SE})$, range of intensity (I) and mean intensity $(\mathrm{MI} \pm \mathrm{SE})$ of helminth parasites in Artemia franciscana in La Tapa

\begin{tabular}{|c|c|c|c|c|}
\hline & $\mathrm{P} \%$ & $\mathrm{MA} \pm \mathrm{SE}$ & I & $\mathrm{MI} \pm \mathrm{SE}$ \\
\hline \multicolumn{5}{|l|}{ December $2006(N=200)$} \\
\hline Flamingolepis liguloides & 0.5 & $0.015 \pm 0.015$ & $3-3$ & 3.00 \\
\hline Flamingolepis flamingo & 3.5 & $0.035 \pm 0.013$ & $1-1$ & 1.00 \\
\hline Eurycestus avoceti & 1.5 & $0.015 \pm 0.009$ & $1-1$ & 1.00 \\
\hline Total & 5.0 & $0.065 \pm 0.022$ & $1-3$ & $1.30 \pm 0.22$ \\
\hline \multicolumn{5}{|l|}{ February $2007(\mathrm{~N}=200)$} \\
\hline Flamingolepis liguloides & 0.5 & $0.005 \pm 0.005$ & $1-1$ & 1.00 \\
\hline Flamingolepis flamingo & 8.5 & $0.090 \pm 0.021$ & $1-2$ & $1.06 \pm 0.06$ \\
\hline Eurycestus avoceti & 5.0 & $0.055 \pm 0.018$ & $1-2$ & $1.10 \pm 0.10$ \\
\hline Gynandrotaenia stammeri & 0.5 & $0.005 \pm 0.005$ & $1-1$ & 1.00 \\
\hline Total & 13.0 & $0.155 \pm 0.032$ & $1-4$ & $1.19 \pm 0.12$ \\
\hline \multicolumn{5}{|l|}{ April $2007(\mathrm{~N}=200)$} \\
\hline Eurycestus avoceti & 0.5 & $0.005 \pm 0.005$ & $1-1$ & 1.00 \\
\hline Total & 0.5 & $0.005 \pm 0.005$ & $1-1$ & 1.00 \\
\hline \multicolumn{5}{|l|}{ June 2007 ( $\mathrm{N}=200)$} \\
\hline Flamingolepis flamingo & 1.5 & $0.015 \pm 0.009$ & $1-1$ & 1.00 \\
\hline Eurycestus avoceti & 3.5 & $0.035 \pm 0.013$ & $1-1$ & 1.00 \\
\hline Total & 5.0 & $0.050 \pm 0.015$ & $1-1$ & 1.00 \\
\hline \multicolumn{5}{|l|}{ September $2007(\mathrm{~N}=149)$} \\
\hline Flamingolepis flamingo & 2.0 & $0.020 \pm 0.011$ & $1-1$ & 1.00 \\
\hline Eurycestus avoceti & 0.7 & $0.013 \pm 0.013$ & $2-2$ & 2.00 \\
\hline Gynandrotaenia stammeri & 1.3 & $0.013 \pm 0.009$ & $1-1$ & 1.00 \\
\hline Acuariinae gen. sp. & 2.0 & $0.020 \pm 0.011$ & $1-1$ & 1.00 \\
\hline Total & 6.0 & $0.067 \pm 0.023$ & $1-2$ & $1.11 \pm 0.10$ \\
\hline \multicolumn{5}{|l|}{ Overall infection $(\mathrm{N}=949)$} \\
\hline Flamingolepis liguloides & 0.2 & $0.004 \pm 0.004$ & $1-3$ & $2.00 \pm 1.00$ \\
\hline Flamingolepis flamingo & 3.2 & $0.033 \pm 0.006$ & $1-2$ & $1.03 \pm 0.03$ \\
\hline Eurycestus avoceti & 2.3 & $0.025 \pm 0.006$ & $1-2$ & $1.09 \pm 0.06$ \\
\hline Gynandrotaenia stammeri & 0.3 & $0.003 \pm 0.002$ & $1-1$ & 1.00 \\
\hline Acuariinae gen. sp. & 0.3 & $0.003 \pm 0.002$ & $1-1$ & 1.00 \\
\hline Total & 5.9 & $0.068 \pm 0.010$ & $1-4$ & $1.16 \pm 0.07$ \\
\hline
\end{tabular}

(parasites of stilts and avocets, see Smogorzhevskaya 1990), Syncuaria Gil'bert, 1927 (parasites of storks and ibises, see Mutafchiev and Georgiev 2008b), Sexansocara Sobolev and Sudarikov, 1939 (parasitic in ospreys, see Baruš et al. 1978), Voguracuaria Wong and Anderson, 1993 (parasitic in dunlins, see Wong and Anderson 1993) or Echinuria Soloviev, 1912 (parasitic in grebes, gulls and ducks, see Baruš et al. 1978; Smogorzhevskaya 1990). All these genera have unknown or poorly-studied life cycles and undescribed (or inadequately characterized) morphology of larval stages (Skryabin et al. 1965; Anderson 2000). Other potential nematode parasites in birds in our study area include the genera Cosmocephalus Molin, 1858 (known from grebes, gulls and redshanks, see Mutafchiev et al. 2010), Skrjabinocerca Shikhobalova, 1930 (parasitic of plovers and sandpipers, see Wong and Anderson 1993), Skrjabinocara Kurashvili, 1940 (parasitic in cormorants, see Smogorzhevskaya 1990), Skrjabinoclava Sobolev, 1943 (parasitic of turnstones, curlews and sandpipers, see Anderson and Wong 1992) or Desportesius Chabaud and Campana, 1949 (mostly parasitic in herons, see Wong and Anderson 1986). However, their larvae are characterized by morphology (as described by Chabaud 1950; Wong and Anderson 1982, 1987; Wong et al. 1989; Bartlett et al. 1989) differentiating them from the nematodes we have recorded here. The elucidation of the diversity of the larval nematodes parasitizing Artemia spp. therefore requires further studies.

The low vulnerability to native parasites of $A$. franciscana can have a wide range of direct and indirect ecological and evolutionary consequences. Given that cestodes are parasites with complex life cycles using food webs for transmission, we expect effects in consumer-resource interactions at different trophic levels. Artemia is the dominant grazer in hypersaline ecosystems and it can control phytoplankton abundance (Mohebbi 2010). Therefore, the lack of regulation of $A$. francis- 
cana population density by parasites (compared with native Artemia populations) may have an impact on phytoplankton density, with potential cascading effects. On the other hand, the density of $A$. franciscana is more likely to become limited by reduced phytoplankton abundance. This is supported by our unpublished observations of $A$. franciscana from the study area affected by Black Spot Disease, which is indicative of dietary deficiency. Similar observations have been reported in A. franciscana from Great Salt Lake in the native range, under unusually low phytoplankton abundance (Lavens and Sorgeloos 1996; Belovsky et al. 2011). We also expect an impact of the invasion on avian communities. Many species of shorebirds are highly dependent on saltpans and Artemia as a food source (Sánchez et al. 2005, 2006b), and prey selection experiments have shown that they selectively feed on infected Artemia, which are more accessible and profitable from an energetic point of view (Sánchez et al. 2009a, 2009b). Therefore waterbirds may have lower foraging intake rates when feeding in salt ponds invaded by $A$. franciscana. Future studies should consider the broader ecological consequences of establishment and spread of the invasive $A$. franciscana.

Finally, it would be interesting to explore the potential role of microorganisms on the successful establishment of $A$. franciscana. Contrary to helminth parasites, which are not present in dormant brine-shrimp eggs ("cysts", i.e. the life-cycle stage in which A. franciscana was introduced), several bacteria, viruses and fungi (mainly microsporidia) have been identified in Artemia cysts and nauplii from the field and from commercial samples (Austin and Allen 1982; Igarashi et al. 1989). Microsporidia in particular can be highly prevalent in invasive populations of $A$. franciscana (Rode et al. 2013) and provoke high levels of mortality in native Artemia populations (personal observation). The potential introduction of novel parasites together with $A$. franciscana into the introduced range and their impact on native host populations should also be assessed.

Acknowledgements. Salinity data were provided by Unión Salinera de España, S.A., thanks to the head of operations Ramón Álvarez. Waterbird census data were provided by the Consejería de Medio Ambiente de la Junta de Andalucía. We are grateful to an anonymous reviewer for the criticism on an earlier version of the manuscript. This work was supported by joint research projects between CSIC and the Bulgarian Academy of Sciences (2004BG0013 and 2005BG 0015), by the EU-funded project WETLANET (FP7, Programme CAPACITIES, Grant 229802) carried out by the Institute of Biodiversity and Ecosystem Research, Bulgarian Academy of Sciences, and by the Spanish Ministry of Science and Innovation (Project CGL2010-16028). The present study used facilities developed at the Institute of Biodiversity and Ecosystem Research, Bulgarian Academy of Sciences, in the framework of the project CEBDER funded by National Science Fund of the Republic of Bulgaria, Grant DOO215/17.02.2009.

\section{References}

Amarouayache M., Derbal F., Kara M.H. 2009. The parasitism of Flamingolepis liguloides (Gervais, 1847) (Cestoda, Hy- menolepididae) in Artemia salina (Crustacea, Branchiopoda) in two saline lakes in Algeria. Acta Parasitologica, 54, 330 334. DOI: $10.2478 / \mathrm{s} 11686-009-0049-8$.

Amat F., Gozalbo A., Navarro J.C., Hontoria F., Varó I. 1991a. Some aspects of Artemia biology affected by cestode parasitism. Hydrobiologia, 212, 39-44. DOI: 10.1007/978-94-011-33661_6.

Amat F., Illescas P., Fernández J. 1991b. Brine shrimp Artemia from Spanish Mediterranean salterns parasitized by Flamingolepis liguloides (Cestoda, Hymenolepididae) cysticercoids. Vie et Milieu, 41, 237-244.

Amat F., Hontoria F., Ruiz O., Green A.J., Sánchez M.I., Figuerola J., Hortas F. 2005. The American brine shrimp Artemia franciscana as an exotic invasive species in the Western Mediterranean. Biological Invasions, 7, 37-47. DOI: 10.1007/s10530004-9634-9.

Amat F., Hontoria F., Navarro J.C., Vieira N., Mura G. 2007. Biodiversity loss in the genus Artemia in the Western Mediterranean region. Limnetica, 26, 387-404.

Anderson R.C. 2000. Nematode Parasites of Vertebrates. Their Development and Transmission. $2^{\text {nd }}$ Edition. CABI Publishing, Wallingford, Oxon (UK), $650 \mathrm{pp}$.

Anderson R.C., Wong P.L. 1992.Western Palaearctic and Ethiopian species of Skrjabinoclava (Nematoda: Acuarioidea) in Icelandic shorebirds (Aves: Charadriiformes) en route to breed in the New World and Greenland. Canadian Journal of Zoology, 70, 1861-1877. DOI: 10.1139/z92-255.

Austin B., Allen D.A. (1982) Microbiology of laboratory-hatched brine shrimp (Artemia). Aquaculture, 26: 369-383. DOI: 10.1016/0044-8486(82)90170-3.

Bartlett C.M., Anderson R.C., Wong P.L. 1989. Development of Skrjabinocerca prima (Nematoda: Acuarioidea) in Hyalella azteca (Amphipoda) and Recurvirostra americana (Aves: Charadriiformes), with comments on its precocity. Canadian Journal of Zoology, 67, 2883-2892. DOI: 10.1139/z89-409.

Baruš V., Sergeeva T.P., Sonin M.D., Ryzhikov K.M. 1978. Helminths of Fish-eating Birds of the Palaearctic Region. I. Nematoda. Academia, Moscow and Prague, $319 \mathrm{pp}$.

Belovsky G.E., Stephens D., Perschon C., Birdsey P., Paul D., Naftz D., Baskin R., Larson C., Mellison C., Luft J., Mosley R., Mahon H., Van Leeuwen J., Allen D.V. 2011. The Great Salt Lake Ecosystem (Utah, USA): long term data and a structural equation approach. Ecosphere, 2, Article 33. DOI: 10.1890/ ES10-00091.1

Bush A.O., Lafferty K.D., Lotz J.M., Shostak A.W. 1997. Parasitology meets ecology on its own terms: Margolis et al. revisited. Journal of Parasitology, 83, 575-583.

Chabaud A.G. 1950. Cycle évolutif de Synhimantus (Desportesius) spinulatus (Nematoda, Acuariidae). Annales de Parasitologie Humaine et Comparée, 25, 150-166.

Chabaud A.G. 1975. Keys to the genera of the order Spirurida. Part 2. Spiruroidea, Habronematoidea and Acuarioidea. In: Anderson RC, Chabaud AG and Willmott S (eds) CIH keys to the nematode parasites of vertebrates, No. 3. Commonwealth Agricultural Bureaux, Farnham Royal, Bucks, 58 pp.

Consejería de Medio Ambiente 2007. Counts of waterbirds at La Tapa Saltpans 2006-2007 (unpublished report). Programa de Emergencias, Control Epidemiológico y Seguimiento de Fauna Silvestre de Andalucía. Junta de Andalucía.

Dunn A.M. 2009. Parasites and biological invasions. Advances in Parasitology, 68, 161-184. DOI: 10.1016/S0065-308X(08) 00607-6

Dunn A.M., Torchin M.E., Hatcher M.J., Kotanen P.M., Blumenthal D.M., Byers J.E., Coon C.A.C., Frankel V.M., Holt R.D., Hufbauer R.A., Kanarek A.R., Schierenbeck K.A., Wolfe L.M., Perkins S.E. 2012. Indirect effects of parasites in invasions. 
Functional Ecology, 26, 1262-1274. DOI: 10.1111/j.13652435.2012.02041.x.

Gabrion C., MacDonald G., Boy V. 1982. Dynamique des populations larvaires du cestode Flamingolepis liguloides dans une population d'Artemia en Camargue. Acta Oecologica, 3, 273-293.

Georgiev B.B., Sánchez M.I., Green A.J., Nikolov P.N., Vasileva G.P., Mavrodieva R.S. 2005. Cestodes from Artemia parthenogenetica (Crustacea, Branchiopoda) in the Odiel Marshes, Spain: a systematic survey. Acta Parasitologica, 50, $105-117$.

Georgiev B.B., Sánchez M.I., Vasileva G.P., Nikolov P.N., Green A.J. 2007. Cestode parasitism in invasive and native brine shrimps (Artemia spp.) as a possible factor promoting the rapid invasion of A. franciscana in the Mediterranean region. Parasitology Research, 101, 1647-1655. DOI: 10.1007/s00436-007-0708-3.

Hortas F. 1997. Evolución de la comunidad de aves limícolas (Orden Charadriiformes) en salinas del suroeste de España. Estructura espacio-temporal de las comunidades y uso del hábitat. $\mathrm{PhD}$ thesis, University of Cádiz, Cádiz

Igarashi M.A., Sugita H., Deguchi Y. 1989. Microflora associated with eggs and nauplii of Artemia salina. Bulletin of the Japanese Society of Scientific Fisheries, 55, 2045.

Kelly D.W., Paterson R.A., Townsend C.R., Poulin R.R., Tompkins D.M. 2009. Parasite spillback: a neglected concept in invasion ecology. Ecology, 90, 2047-2056. DOI: 10.1890/081085.1 .

Lavens P., Sorgeloos P. (eds.) 1996. Manual on the production and use of live food for aquaculture. FAO Fisheries Technical Paper. No. 361. FAO, Roma, 295 pp.

Mohebbi F. 2010. The brine shrimp Artemia and hypersaline environments microalgal composition: a mutual interaction. International Journal of Aquatic Science, 1, 19-27

Muñoz J., Gómez A., Figuerola J., Amat F., Rico C., Green A.J. 2014. Colonization and dispersal patterns of the invasive American brine shrimp Artemia franciscana (Branchiopoda: Anostraca) in the Mediterranean region. Hydrobiologia, 726, 25-41. DOI: $10.1007 / \mathrm{s} 10750-013-1748-6$

Mura G. 1995. Cestode parasitism Flamingolepis liguloides (Gervais, 1847) Spassky \& Spasskaja, 1954 in an Artemia population from south-western Sardinia. International Journal of Salt Lake Research, 3, 191-200. DOI: 10.1007/BF01990494

Mutafchiev Y., Georgiev B.B. 2008a. Redescription of Decorataria decorata (Spirurida, Acuariidae) based on nematodes from Podiceps cristatus and P. grisegena (Aves, Podicipediformes) from Bulgaria. Acta Parasitologica, 53, 158-164. DOI: 10.2478/s11686-008-0016-9.

Mutafchiev Y., Georgiev B.B. 2008b. A new acuariid nematode, Syncuaria mackoi n. sp. (Spirurida), from Ciconia nigra (L.) (Ciconiiformes: Ciconiidae) in Europe. Systematic Parasitology, 70, 71-79. DOI: 10.1007/s11230-008-9138-6.

Mutafchiev Y., Halajian A., Georgiev B.B. 2010. Two new nematode species of the genus Cosmocephalus Molin, 1858 (Spirurida: Acuariidae), with an amended generic diagnosis and an identification key to Cosmocephalus spp. Zootaxa, 2349, 1-20.

Redón S., Amat F., Hontoria F., Vasileva G.P., Nikolov P.N., Georgiev B.B. 2011. Participation of metanauplii and juvenile individuals of Artemia parthenogenetica (Branchiopoda) in the circulation of avian cestodes. Parasitology Research, 108, 905-912. DOI: 10.1007/s00436-010-2132-3.

Robert F., Gabrion C. 1991. Cestodoses de l'avifaune camarguaise. Rôle d'Artemia (Crustacea, Anostraca) et stratégies de rencontre hôte-parasite. Annales de Parasitologie Humaine et Comparée, 66, 226-235.

Rode N.O., Lievens E.J.P., Flaven E., Segard A., Jabbour-Zahab R., Sánchez M.I., Lenormand T. 2013. Why join groups? Lessons from parasite-manipulated Artemia. Ecology Letters, 16, 493 501. DOI: $10.1111 /$ ele.12074.

Sánchez M.I., Green A.J., Castellanos E.M. 2005. Seasonal variation in the diet of Redshank Tringa totanus in the Odiel Marshes, southwest Spain: a comparison of faecal and pellet analysis. Bird Study, 52, 210-216. DOI: 10.1080/00063650509461393.

Sánchez M.I., Georgiev B.B., Nikolov P.N., Vasileva G.P., Green A.J. 2006a. Red and transparent brine shrimps (Artemia parthenogenetica): a comparative study of their cestode infections. Parasitology Research, 100, 111-114. DOI: 10.1007/s00436006-0248-2.

Sánchez M.I., Green A.J., Castellanos E.M. 2006b. Spatial and temporal fluctuations in presence and use of chironomid prey by shorebirds in the Odiel saltpans, south-west Spain. Hydrobiologia, 567, 329-340. DOI: 10.1007/s10750-006-0060-0.

Sánchez M.I., Georgiev B.B., Green A.J. 2007. Avian cestodes affect the behaviour of their intermediate host Artemia parthenogenetica: an experimental study. Behavioural Processes, 74, 293-299. DOI: 10.1016/j.beproc.2006.11.002.

Sánchez M.I., Hortas F., Figuerola J., Green A.J. 2009a. Sandpipers select red brine shrimps rich in both carotenoids and parasites. Ethology, 115, 196-200. DOI: 10.1111/j.1439-0310.2008. 01601.x.

Sánchez M.I., Thomas F., Perrot-Minnot M.J., Biron D.G., BertrandMichel J., Missé D. 2009b. Neurological and physiological disorders in Artemia harbouring manipulative cestodes. Journal of Parasitology, 95, 20-24. DOI: 10.1645/GE-1550.1.

Sánchez M.I., Rode N.O., Flaven E., Redón S., Amat F., Vasileva G.P., Lenormand T. 2012. Differential susceptibility to parasites of invasive and native species of Artemia living in sympatry: consequences for the invasion of $A$. franciscana in the Mediterranean region. Biological Invasions, 14, 1819-1829. DOI: $10.1007 / \mathrm{s} 10530-012-0192-2$.

Sánchez M.I., Varo N., Matesanz C., Ramo C., Amat J.A., Green A.J. 2013a. Cestodes change the isotopic signature of brine shrimp Artemia hosts: implications for aquatic food webs. International Journal for Parasitology, 43, 73-80. DOI: 10.1016/j.ijpara.2012.11.003

Sánchez M.I., Nikolov P.N., Georgieva D.D., Georgiev B.B., Vasileva G.P., Pankov P., Paracuellos M., Lafferty K.D., Green A.J. 2013b. High prevalence of cestodes in Artemia spp. throughout the annual cycle: relationship with abundance of avian final hosts. Parasitology Research, 112, 1913-1923. DOI: $10.1007 / \mathrm{s} 00436-013-3347-\mathrm{x}$.

Skryabin K.I., Sobolev A.A., Ivashkin V.M. 1965. [Spirurata of Animals and Man and the Diseases Caused by Them. Spirurata. Part 3. Acuarioidea.] In: Skryabin KI (ed) Osnovy Nematodologii. Volume 14. Izdatel'stvo Nauka, Moscow, 572 pp. (In Russian).

Smogorzhevskaya L.A. 1990. [Nematodes. Part 3. Acuarioidea]. In: Sharpilo V.P. (ed), Fauna Ukrainy, Volume 32. Naukova Dumka, Kiev, 189 pp. (In Russian).

Snow D.W., Perrins C.M., Hillcoat B., Gillmor R., Roselaar C.S. 1998. The birds of the Western Palaearctic, concise edition. Oxford University Press, Oxford, New York, 1697 pp.

Thiéry A., Robert F., Gabrion R. 1990. Distribution des populations d'Artemia et de leur parasite Flamingolepis liguloides (Cestoda, Cyclophyllidea) dans les salins du littoral méditerranéen français. Canadian Journal of Zoology, 68, 2199-2204. DOI: 10.1139/z90-305.

Varó I., Taylor A.C., Navarro J.C., Amat F. 2000. Effect of parasitism on the respiration rates of adults of different Artemia strains from Spain. Parasitology Research, 86, 772-774. DOI: 10. 1007/s004360000236.

Vasileva G.P., Redón S., Amat F., Nikolov P.N., Sánchez M.I., Lenormand T., Georgiev B.B. 2009. Records of cysticercoids of 
Fimbriarioides tadornae Maksimova, 1976 and Branchiopodataenia gvozdevi (Maksimova, 1988) (Cyclophyllidea: Hymenolepididae) from brine shrimps at the Mediterranean coasts of Spain and France, with a key to cestodes from Artemia spp. from the Western Mediterranean. Acta Parasitologica, 54, 143-150. DOI: 10.2478/s11686-009-0025-3.

Vikas P.A., Sajeshkumar N.K., Thomas P.C., Chakraborty K., Vijayan K.K. 2012. Aquaculture related invasion of the exotic Artemia franciscana and displacement of the autochthonous Artemia populations from the hypersaline habitats of India. Hydrobiologia, 684, 129-142. DOI: 10.1007/s10750-011-0976-x.

Wong P.L., Anderson R.C. 1982. The transmission and development of Cosmocephalus obvelatus (Nematoda: Acuarioidea) of gulls (Laridae). Canadian Journal of Zoology, 60, 1426-1440. DOI: $10.1139 / z 82-192$

Wong P.L., Anderson R.C. 1986. Revision of the genus Desportesius Chabaud and Campana, 1949 (Nematoda: Acuarioidea) mainly from the gizzard of ciconiiform birds. Canadian Journal of Zoology, 64, 2520-2530. DOI: 10.1139/z86-373.

Wong P.L., Anderson R.C. 1987. Development of Syncuaria squamata (Linstow, 1883) (Nematoda: Acuarioidea) in ostracods (Ostracoda) and double-crested cormorants (Phalacrocorax auritus auritus). Canadian Journal of Zoology, 65, 25242531. DOI: $10.1139 / \mathrm{z} 87-381$.

Wong P.L., Anderson R.C. 1993. New and described species of nematodes from shorebirds (Charadriiformes) collected in spring in Iceland. Systematic Parasitology, 25, 187-202. DOI: 10.1007/BF00007008.

Wong P.L., Anderson R.C., Bartlett C.M. 1989. Development of Skrjabinoclava inornata (Nematoda: Acuarioidea) in fiddler crabs (Uca spp.) (Crustacea) and Western Willets (Catoptrophorus semipalmatus inornatus) (Aves: Scolopacidae). Canadian Journal of Zoology, 67, 2893-2901. DOI: 10.1139/ z89-410.

Received: September 10, 2013

Revised: March 19, 2014

Accepted for publication: April 7, 2014

Appendix I. Mean values of monthly waterbird counts at the La Tapa salterns for the period from January 2006 to December 2007 and their conversion into biomass ( $\mathrm{g}$ ) based on Snow et al. (1998)

\begin{tabular}{|c|c|c|}
\hline Bird groups and species & Mean count & Mean biomass \\
\hline \multicolumn{3}{|l|}{ Grebes (Podicipedidae) } \\
\hline Great Crested Grebe (Podiceps cristatus) & 0.04 & 43.77 \\
\hline \multicolumn{3}{|l|}{ Cormorants (Phalacrocoracidae) } \\
\hline Great Cormorant (Phalacrocorax carbo) & 70.33 & 161766.67 \\
\hline \multicolumn{3}{|l|}{ Herons and Egrets (Ardeidae) } \\
\hline Cattle Egret (Bubulcus ibis) & 4.13 & 1443.75 \\
\hline Little Egret (Egretta garzetta) & 8.50 & 3825.00 \\
\hline Grey Heron (Ardea cinerea) & 21.71 & 33571.94 \\
\hline \multicolumn{3}{|l|}{ Storks (Ciconiidae) } \\
\hline White Stork (Ciconia ciconia) & 0.46 & 1535.42 \\
\hline \multicolumn{3}{|l|}{ Ibises and Spoonbills (Threskiornithidae) } \\
\hline Common Spoonbill (Platalea leucorodia) & 32.00 & 49440.00 \\
\hline \multicolumn{3}{|l|}{ Flamingos (Phoenicopteridae) } \\
\hline Greater Flamingo (Phoenicopterus roseus) & 836.79 & 2614973.96 \\
\hline \multicolumn{3}{|l|}{ Ducks and Geese (Anatidae) } \\
\hline Common Shelduck (Tadorna tadorna) & 3.13 & 3476.56 \\
\hline Common Teal (Anas crecca) & 0.04 & 13.54 \\
\hline Mallard (Anas platyrhynchos) & 5.71 & 6065.10 \\
\hline Northern Shoveler (Anas clypeata) & 7.33 & 4620.00 \\
\hline \multicolumn{3}{|l|}{ Ospreys (Pandionidae) } \\
\hline Osprey (Pandion haliaetus) & 0.67 & 1166.67 \\
\hline \multicolumn{3}{|l|}{ Rails (Rallidae) } \\
\hline Eurasian Coot (Fulica atra) & 3.04 & 2433.33 \\
\hline \multicolumn{3}{|l|}{ Gulls and Terns (Laridae) } \\
\hline Mediterranean Gull (Larus melanocephalus) & 0.04 & 10.67 \\
\hline Black-headed Gull (Chroicocephalus ridibundus) & 118.92 & 34188.54 \\
\hline Slender-billed Gull (Larus genei) & 11.08 & 3175.38 \\
\hline Audouin's Gull (Larus audouinii) & 5.214 & 010.42 \\
\hline Lesser Black-backed Gull (Larus fuscus) & 101.46 & 79873.07 \\
\hline Yellow-legged Gull (Larus michahellis) & 2098.25 & 2486426.25 \\
\hline
\end{tabular}




\begin{tabular}{|c|c|c|}
\hline Caspian Tern (Sterna caspia) & 0.54 & 367.25 \\
\hline Sandwich Tern (Sterna sandvicensis) & 26.25 & 6431.25 \\
\hline Common Tern (Sterna hirundo) & 3.33 & 433.33 \\
\hline Little Tern (Sternula albifrons) & 43.33 & 2426.67 \\
\hline Whiskered Tern (Chlidonias hybridus) & 0.25 & 22.88 \\
\hline Black Tern (Chlidonias niger) & 95.17 & 5900.33 \\
\hline \multicolumn{3}{|l|}{ Shorebirds } \\
\hline \multicolumn{3}{|l|}{ Oystercatchers (Haematopodidae) } \\
\hline Eurasian Oystercatcher (Haematopus ostralegus) & 1.38 & 742.50 \\
\hline \multicolumn{3}{|l|}{ Stilts and Avocets (Recurvirostridae) } \\
\hline Black-winged Stilt (Himantopus himantopus) & 137.92 & 24825.00 \\
\hline Eurasian Avocet (Recurvirostra avosetta) & 375.54 & 103273.96 \\
\hline \multicolumn{3}{|l|}{ Stone curlews (Burhinidae) } \\
\hline Eurasian Stone Curlew (Burhinus oedicnemus) & 38.83 & 18057.50 \\
\hline \multicolumn{3}{|l|}{ Plovers (Charadriidae) } \\
\hline Common Ringed Plover (Charadrius hiaticula) & 75.58 & 4837.33 \\
\hline Kentish Plover (Charadrius alexandrinus) & 91.46 & 4344.27 \\
\hline Grey Plover (Pluvialis squatarola) & 34.21 & 9920.42 \\
\hline \multicolumn{3}{|l|}{ Sandpipers and Allies (Scolopacidae) } \\
\hline Red Knot (Calidris canutus) & 0.33 & 59.17 \\
\hline Sanderling (Calidris alba) & 50.00 & 4012.50 \\
\hline Little Stint (Calidris minuta) & 54.63 & 1843.59 \\
\hline Curlew Sandpiper (Calidris ferruginea) & 154.71 & 12415.34 \\
\hline Dunlin (Calidris alpina) & 283.96 & 13488.02 \\
\hline Ruff (Philomachus pugnax) & 0.04 & 7.60 \\
\hline Black-tailed Godwit (Limosa limosa) & 195.50 & 60116.25 \\
\hline Bar-tailed Godwit (Limosa lapponica) & 46.83 & 15455.00 \\
\hline Whimbrel (Numenius phaeopus) & 0.75 & 406.88 \\
\hline Eurasian Curlew (Numenius arquata) & 1.21 & 1069.38 \\
\hline Green Sandpiper (Tringa ochropus) & 0.08 & 7.79 \\
\hline Common Redshank (Tringa totanus) & 91.67 & 10656.25 \\
\hline Common Greenshank (Tringa nebularia) & 2.96 & 591.67 \\
\hline Common Sandpiper (Actitis hypoleucos) & 0.58 & 35.00 \\
\hline Ruddy Turnstone (Arenaria interpres) & 9.42 & 1106.46 \\
\hline Phalarope (Phalaropus tricolor) & 0.04 & 0.01 \\
\hline
\end{tabular}

